\title{
Formas de tratamento: português e espanhol em foco
}

\author{
Forms of treatment: Portuguese and Spanish in focus \\ Luiz Antônio da Silva \\ Ramiro Carlos Humberto Caggiano Blanco \\ Yedda Alves de Oliveira Caggiano Blanco \\ Universidade de São Paulo - São Paulo, SP, Brasil
}

\begin{abstract}
Resumo: Ser competente linguisticamente, além de dominar as regras morfossintáticas e a semântica próprias de cada língua, é conhecer também o conjunto de normas que regulam o comportamento adequado dos membros de um determinado meio social. A língua, como meio de interação com outros indivíduos, não pode ser desvinculada de suas características socioculturais. Ao respeito, cada sociedade estabelece regras, nas quais se incluem as formas de tratamento, que sancionam as condutas comunicativas como sendo adequadas ou inadequadas. A forma como tratamos o outro se insere num código social que, quando transgredido, pode causar prejuízo no relacionamento entre os interlocutores. Especificamente, as formas de tratamento designam tanto os termos que se referem ao par falante-ouvinte, como os vocativos usados para chamar a atenção do destinatário, englobando os chamados pronomes pessoais de tratamento assim como as formas nominais. O objetivo deste trabalho é fazer considerações sobre as formas de tratamento no português do Brasil e no espanhol ibérico; apresentar teorias que abordam o tema da cortesia; e, a partir de dados obtidos de duas obras de teatro brasileiras do século XX, analisar e comparar as estratégias pragmáticas desenvolvidas mediante as formas de tratamento tanto no português do Brasil como no espanhol ibérico. Com este estudo, pretendemos, também, oferecer aos professores de língua estrangeira algumas apreciações acerca das dificuldades, pragmalinguísticas e sociopragmáticas que, no processo de aquisição/aprendizagem das formas de tratamento, podem ocorrer por influência da língua materna.
\end{abstract}

Palavras-chave: Interação; Formas de tratamento; Cortesia; Aquisição

\begin{abstract}
Being linguistically competent is, besides mastering the morphosyntactic rules and semantics of each language, it is also to know the set of norms that regulate the proper behavior of the members of a particular social environment. Language, as a means of interaction with other individuals, cannot be detached from its sociocultural characteristics. To the respect, each society establishes rules, which include the forms of treatment that sanction the conduct of communicative behaviors as being adequate or inadequate. The way we treat others is embedded in a social code that, when transgressed, can cause damage in the relationship between the interlocutors. Specifically, forms of treatment designate both the terms that refer to the speaker-hearer pair, as the vocatives used to draw the attention of the recipient, including the so-called personal pronouns of treatment as well as the nominal forms. The purpose of this work is to make considerations about the forms of treatment in Brazilian Portuguese and Iberian Spanish; present theories that address the subject of courtesy; and finally, on the basis of data obtained from two works of Brazilian theater of the 20th century, analyze and compare the pragmatic strategies developed through the forms of treatment in both Brazilian Portuguese and Iberian Spanish. With this study we also intend to offer teachers of foreign language some appreciation of the difficulties, pragmalinguistic and sociopragmatic, that in the process of acquisition/learning of the forms of treatment may occur due to the influence of the mother tongue.
\end{abstract}

Keywords: Interaction; Forms of treatment; Politeness; Acquisition/learning 


\section{Considerações iniciais}

A língua é um meio para a interação com outros indivíduos, sendo assim, é usada diariamente e, muitas vezes, as pessoas não reconhecem o quanto é importante. Como não se pode desvincular língua e sociedade, é necessário conhecer o conjunto de normas que regulam o comportamento adequado dos membros de um meio social. Cada sociedade estabelece regras que regulam tais comportamentos e as formas de tratamento fazem parte dessas regras sociais que sancionam determinados comportamentos como adequados ou inadequados.

Quando duas ou mais pessoas conversam, uma pode dirigir-se à outra empregando um nome ou um pronome, que cumprirão a função de chamar a atenção do interlocutor. O tratamento é, pois, um sistema de significação que abarca diversas modalidades de dirigir-se a uma pessoa. Trata-se de um código social que, quando se transgride, pode causar prejuízo no relacionamento entre os interlocutores.

Por formas de tratamento designamos tanto os termos que se referem ao par falante-ouvinte, como os vocativos usados para chamar a atenção do destinatário. Assim, as formas de tratamento englobam tanto os chamados pronomes pessoais de tratamento como as formas nominais, isto é, o uso de nomes próprios, títulos, apelidos e outras formas nominais que identifiquem a pessoa referida.

Pedroviejo Esteruelas (2004) estudou as formas de tratamento e cortesia no espanhol peninsular, a partir de obras de teatro do século XX. Segundo o autor, "as fórmulas de tratamento, tanto nominais como pronominais, variam e adquirem diferentes valores, porque nelas incidem fatores temporais, sociais, de gênero e de idade." Ainda que focalizemos outro ambiente e consideremos outro idioma, é possível verificar que o sistema de tratamentos no português do Brasil está mais próximo do espanhol do que do português de Portugal.

O objetivo deste trabalho é fazer algumas considerações sobre as formas de tratamento no português do Brasil à luz das teorias que abordam o tema da cortesia e comparar os dados obtidos no português do Brasil com dados do espanhol ibérico. Para levar a cabo os objetivos deste trabalho, analisamos duas obras de teatro brasileiras do século XX. Também, temos por objetivo, oferecer aos professores de L2 ferramentas adequadas quanto ao uso das formas de tratamento no português do Brasil e em espanhol peninsular, pois se mostram de formas diferentes e diversas.

Cientes de que, ao aprendermos uma nova língua, não só os aspectos gramaticais e lexicais são importantes, mas também os aspectos pragmáticos, neste trabalho explicitaremos as diferenças gramaticais, pragmalinguísticas e sociopragmáticas da realização dos enunciados em ambas as línguas sob estudo.

\section{Aquisição/aprendizagem de L2}

O processo de aquisição de uma língua pressupõe o questionamento inicial do próprio termo, isto é, o que é a aquisição de uma língua? E, mais específico ainda, o que é uma aquisição de uma segunda língua?

A aquisição da língua está relacionada ao mecanismo natural como aprendemos a nossa língua materna, num processo que abrange uma competência linguística de total comunicação entre os sujeitos envolvidos, ao passo que a aquisição de uma segunda língua está associada a um processo de aprendizagem por parte do sujeito aprendente de novas formas que o faça ser competente linguisticamente nesta língua. Dessa forma, há lingüistas, como Krashen (1982), que distinguem os termos de aquisição ao de aprendizagem, pois, para ele, a aquisição é um processo automático, inconsciente do sujeito, já a aprendizagem é um processo consciente sobre o funcionamento da língua e, ainda, só haverá equivalência dos termos aquisição e aprendizagem, se o aprendiz se tornar competente comunicativamente na L2. Outros, como Schultz (2006), no entanto, ao colocar que a Language acquisition "refere-se ao processo de assimilação natural, intuitivo, subconsciente, fruto de interação em situações reais de convívio humano em ambientes da língua e da cultura estrangeira, em que o aprendiz participa como sujeito ativo", enfatiza a importância da interação no processo de aprendizagem como elemento que fará com que o aprendente seja capaz de um entendimento oral, seja capaz de identificar e distinguir aspectos culturais envolvidos no processo de aquisição. Assim, para o nosso trabalho, adotaremos o termo aquisição/aprendizagem, da mesma forma que L2 também se referirá à língua estrangeira.

Tornar-se competente linguisticamente é o objetivo do sujeito aprendente, no sentido que, ao fazer uso da L2, seja tão natural quanto à de um falante nativo. Mais ainda, saber fazer uso das competências pragmáticas da língua. Fraser (2010) define que a competência pragmática: "is the ability to communicate your intended message with all its nuances in any socio-cultural context and to interpret the message of your interlocutor as it was intended". Essa definição nos faz crer que adquirir uma língua é algo complexo e envolve elementos não só estruturais, mas também, no dizer dele, as nuances em determinado contexto.

Temos que observar, entretanto, que o sujeito aprendente de L2 é distinto de um nativo e por esta razão ele carrega em si um sistema de língua inicial que o coloca como um sujeito observador alheio à realidade da $\mathrm{L} 2$. 
Isso significa que, no processo, pode ocorrer a conhecida interlíngua, isto é, a interferência que a língua materna produz no processo de aquisição da L2.

A esse respeito, VanPatten, Bill; Benati, Alessandro G. (2010) apresentam três aspectos que influenciam ou favorecem a criação deste fenômeno: a) transferência do sistema linguístico da L1 para a L2, resultando em aspectos positivos ou negativos; b) o uso da generalização, isto é, os aprendentes usam as regras do L2 para todas as estruturas e c) a simplificação, na qual os aprendentes usam a L2 de forma reduzida, quase infantilizada.

Como podemos perceber, a aquisição/aprendizagem de uma nova língua supõe um complexo processo e, portanto, requer uma série de ações, ou pelo menos estudos, para minimizar o impacto da assimilação da L2 por parte do aprendente.

Neste artigo, analisaremos como, no processo de aprendizado de espanhol como L2 por falantes de português do Brasil, podem ocorrer interferências ocasionadas nas formas internalizadas da língua materna por eles, e que podem significar um obstáculo para a aquisição das formas em espanhol. Correa (2010, p. 21) aponta que "el estado cognitivo inicial del que parten los brasileños en dirección a su aprendizaje del español es su lengua materna, el PB. Los dados demuestran que, al menos en las etapas iniciales de interlengua, la producción del aprendiz está atravesada por estrategias cognitivas y parámetros sintácticos de PB". Mais ainda, observaremos como esta interferência atua na interação entre falantes que compartilham L1 e L2 distintas, ocasionando problemas à imagem.

\section{Formas de tratamento}

Segundo Kerbrat-Orecchini (1996, p. 73), as formas de tratamento englobam um conjunto de expressões das quais o usuário da língua dispõe para interagir com seu interlocutor. Fazem parte destas formas de tratamento os pronomes pessoais e as formas nominais.

Entendemos por formas de tratamento palavras ou sintagmas que o usuário da língua emprega para dirigir-se e/ou referir-se a outro indivíduo. Estabelecemos quatro níveis para tais formas:

1. Formas pronominalizadas, isto é, palavras e expressões que equivalem a verdadeiros pronomes de tratamento, como as formas você, o senhor, a senhora.

2. Formas nominais, constituídas por nomes próprios, nomes de parentesco, nomes de função (como professor, doutor, etc.).

3. Formas vocativas, isto é, palavras desvinculadas da estrutura argumentativa do enunciado e usadas para designar ou chamar a pessoa com quem se fala. Normalmente, tais formas estão acompanhadas de pronomes pessoais explícitos ou implícitos.

4. Outras formas referenciais, ou seja, palavras usadas como referência à pessoa de quem se fala.

Em geral, a sociedade está dividida por hierarquia, por isso o tratamento que recebe um membro da sociedade depende do papel que desempenha e de suas características: idade, gênero, posição familiar, hierarquia profissional, grau de intimidade, etc. Sendo assim, cada um deve tratar o outro de acordo com as posições relativas que ambos ocupam na escala social. Considera-se descortês o fato de uma pessoa dirigir-se a um superior hierárquico com excessiva familiaridade. Caso isso ocorra, o superior poderá imaginar que o interlocutor deseja algum favor ou que, habitualmente, transgride as normas sociais. Da mesma forma, é inadequado dirigir-se a um amigo íntimo de maneira formal. Se tal fato ocorrer, pode ser um sinal evidente de desejo de distanciamento da relação amistosa ou de artificialidade no comportamento social.

O uso das formas de tratamento é a expressão linguística da estrutura vigente em um determinado meio social. O emprego dos tratamentos não depende, propriamente, do sistema linguístico, mas da forma como a sociedade está organizada. No Brasil, pós-ditadura militar, houve profundas mudanças na sociedade, especialmente em relação à liberalização de costumes. É evidente que os tratamentos seguiram também tais mudanças e, não raramente, refletem os costumes mais liberais que vêm caracterizando a sociedade brasileira dos últimos tempos.

Desde a introdução por Brown e Gilman (1960), o conceito da dinâmica de poder e solidariedade tem tido um papel fundamental na visão sociolinguística. $\mathrm{O}$ trabalho desses autores centra-se, fundamentalmente, na análise das interrelações entre a estrutura linguística e as estruturas sociais, já que a sociedade está polarizada entre duas forças - poder e solidariedade -, que retratam relações que se estabelecem entre os interlocutores. Os autores concluem que, desde o final do século XIX, estáse produzindo uma mudança de direção rumo à supressão do eixo semântico de poder a favor do eixo semântico de solidariedade. Há uma diminuição da frequência de tratamento assimétrico e um aumento correspondente ao tratamento simétrico. Essa mudança linguística estaria associada às mudanças e aos valores adquiridos no século $\mathrm{XX}$, como são as consequências de sociedades mais abertas e igualitárias que acarretam o aumento do uso de formas simétricas. Também, no âmbito da solidariedade informal, estendeu-se, pois, o número de relações consideradas suficientemente solidárias.

Os autores ressaltam que, depois, da Segunda Guerra Mundial, houve uma abertura maior nas estruturas sociais, o que possibilitou uma mobilidade mais acentuada nas 
hierarquias, provocando renovação nos sistemas de tratamento. Dessa forma, nas línguas europeias, houve uma mudança do predomínio de relações assimétricas para um predomínio de relações simétricas. É possível pensar em uma solidariedade formal, marcada por relações recíprocas formais (em francês, vous/vous; em espanhol, usted/usted; no português do Brasil, o senhor/ o senhor; no português de Portugal, uma série de formas, como o senhor/o senhor, Vossa Excelêncial Vossa Excelência,etc.) e em uma solidariedade informal, marcada por relações recíprocas informais (em francês, tu/tu; em espanhol, tú/tú; no português do Brasil, vocêl você; no português de Portugal, tu/tu). As sociedades fechadas do passado, pouco a pouco, transformaram-se nas sociedades abertas do presente. A força da expansão da solidariedade derrubou ou, pelo menos, está exercendo uma forte pressão sobre o poder. Com isso, a primazia do poder cede lugar à primazia da solidariedade.

Ressalte-se que, no português do Brasil, as mudanças são muito similares às ocorridas no espanhol. Assim, Robinson (1977) assinala que, quando se trata de formas de tratamento, as convenções já existem e as normas que governam o emprego diferenciado podem ser levadas para as diferentes relações entre papéis sociais. Nas relações em que estão envolvidos direitos e deveres que impliquem desequilíbrio de poder, as formas assimétricas de tratamento são mais suscetíveis de ocorrer. Na sociedade atual, tais relações manifestam-se nas diferenças de faixa etária (crianças e adultos) e de profissão (empregador/ empregado).

Talvez, por suas características econômicas e sociais, Espanha e Brasil apresentam características muito semelhantes no que se refere às formas de tratamento. Ainda que o código seja o mesmo, há diferenças mais profundas entre o sistema de tratamentos do português de Portugal e do português do Brasil. Lindley Cintra (1972) escreveu um dos trabalhos mais importantes sobre as formas de tratamento no português de Portugal. Segundo o autor, uma das características marcantes se refere aos tratamentos do tipo nominal, muito frequentes em Portugal e pouco usados no Brasil. Além disso, os tratamentos do português de Portugal apresentam um sistema tríplice (ternário), enquanto os tratamentos no Brasil seguem um sistema dual, muito parecido com o espanhol.

O português de Portugal apresenta as seguintes formas:

a) Formas próprias da intimidade: $t u$.

b) Formas usadas no tratamento de igual para igual (ou de superior para inferior) e que não implicam intimidade: você.

c) Formas de reverência, repartidas em uma série variada de níveis, correspondentes a distâncias diversas entre os interlocutores: o senhor, Vossa Excelência, o senhor Doutor, o senhor professor Doutor, etc.

O português do Brasil apresenta as seguintes formas:

a) Tratamento próprio da intimidade: você (A forma $t u$ está restrita a algumas regiões e a alguns bolsões linguísticos).

b) Tratamento formal: o senhor, a senhora.

O espanhol ibérico, por sua vez, apresenta as seguintes formas:

a) Tratamento próprio da intimidade: tú (A forma vos é equivalente a tú em muitas regiões de América).

b) Tratamento formal: usted.

Especificamente falando do espanhol em comparação com o português do Brasil, embora, como afirma Almeida Filho (1995, p.14), o português e o espanhol sejam as línguas românicas mais próximas, nas formas de tratamento existem diferenças morfossintáticas e semânticas significativas que dificultam o processo de aprendizagem/aquisição.

A principal delas tem a ver com a não equivalência semântica dos pronomes você, em português com seu homônimo espanhol usted. Como afirma Nair Floresta Andrade Neta,

Los brasileños suelen confundirse en el uso de la forma "Usted" con valor formal puesto que la comparan con el você del portugués de uso informal (equivalente a "tú" en la mayor parte del país). Quizás este error se debe al hecho de que la concordancia con você se hace en la tercera persona como con "usted" en español. Es decir, utilizan "usted" cuando su intención es utilizar el tratamiento informal o bien, utilizan el pronombre "tú" pero hacen la concordancia verbal en tercera persona o viceversa (2012).

Apesar de que, como explica Lathrop, o pronome de tratamento usted tenha uma procedência histórica ${ }^{1}$ muito semelhante a você do português, em espanhol empregase usted para definir distanciamento ou hierarquia social, enquanto, em português, acontece o contrário com a forma você.

Em decorrência desse fato há, em espanhol, duas formas verbais diferenciadas para definir a forma de tratamento: a segunda pessoa do singular (tú) para a informalidade, e a terceira do singular (usted) para a formalidade (Di TULLIO, 2007, p. 169). No português, só há a terceira do singular e, por tal motivo, a marca diferenciadora da distância social recai no próprio emprego dos pronomes de tratamento, você ou $o$ senhor/a, que, por tal motivo, se fazem necessários para

\footnotetext{
Segundo Lathrop, Usted procede de una versión desgastada de vuestra merced, pasando por formas abreviadas como vuasted, vuested y vusted.
} 
tal distinção (CUNHA, 1975, p.291). Como consequência desse aspecto diferencial, ambas as línguas, como explica González (1998, p. 247), apresentam uma distância assimétrica quanto ao emprego de formas pronominais plenas ou nulas: enquanto o português do Brasil é uma língua de sujeito pronominal predominantemente pleno, o espanhol, por sua vez, é claramente uma língua de sujeitos pronominais predominantemente nulos. Assim, em espanhol, por exemplo, para perguntar formalmente pelo nome do interlocutor uma possibilidade seria: ¿Cómo se llama? enquanto que, em português, seu equivalente empregaria, necessariamente, o pronome de tratamento: Como o senhor / a senhora se chama?

Outro aspecto, decorrente do anterior, que diferencia ambas as línguas no modo de estruturar a sintaxe das formas de tratamento, reside no emprego dos pronomes oblíquos. Em princípio, as normas gramaticais dos pronomes oblíquos de terceira pessoa do português e do espanhol são quase idênticas $(o / a$ / lhe e lo / la / le respectivamente) assim como o pronome reflexivo se. Contudo, neste ponto também as diferenças quanto ao uso se fazem presentes, como explica Fanjul:

Enquanto no espanhol os pronomes átonos com função de objeto direto (me, te, lo/la/ -s nos os) ocorrem em qualquer registro de língua, desde os mais formais até os mais informais ou ainda vulgares e na fala de todos os setores sociais, qualquer que seja seu grau de escolaridade, no português brasileiro alguns dos equivalentes desses pronomes, sobretudo os de terceira pessoa (o,aos, as e seus alomorfes), ocorrem apenas em enunciados com fortes requisitos de formalidade, predominantemente escritos, e o"acerto" no seu uso parece requerer, mesmo para os brasileiros escolarizados, um tipo de especulação reflexiva mais próprias do emprego de estruturas de uma língua não materna (2014, p. 40-41, negrito do autor).

Desta forma, em espanhol são corretas as seguintes possibilidades: Lo/La espero / Lo/La ayudo, porém são agramaticais os enunciados \#Espero usted /\#Ayudo usted. Em português, ambas as possibilidades são gramaticalmente corretas, embora as formas com os pronomes átonos de objeto direto (Eu o/a ajudo e Eu a/o espero), como explica Fanjul, são difíceis de serem empregadas no português do Brasil, preferindo-se seus equivalentes Eu ajudo o senhor/a senhora e Eu espero o senhor/a senhora.

Estabelece-se, assim, um breve panorama das dificuldades que as diferenças semânticas e morfossintáticas entre o português do Brasil e o espanhol, que os estudantes brasileiros têm que transpor ao estudar a segunda das línguas quanto à distinção das formas de tratamento. Estas dificuldades, não raramente, apresentam interferências no processo de aprendizagem/aquisição pela ação da língua materna na L2.

Em seguida, serão tratados os aspectos pragmáticos das formas de tratamento.

\section{Cortesia e formas de tratamento}

Em seu trabalho, Lakoff (1973) faz uma releitura do trabalho de Grice sobre as Máximas Conversacionais, propondo uma série de regras de cortesia, destinadas a limitar ao máximo o risco potencial de conflito em qualquer interação verbal. Ao propor tais máximas, Lakoff tinha por objetivo mostrar que, nem sempre, as máximas propostas por Grice precisam ser respeitadas. Qual é o objetivo básico da interação? Ser claro e romper a interação ou manter a interação? Dessa forma, é possível valer-se de artifícios linguísticos que permitem discutir determinado tema polêmico, mas de forma que não se interrompa a interação.

Essas regras que regem o comportamento do falante podem ser resumidas em três máximas:

1. Não imponha! Mantenha a distancia! O comportamento linguístico do locutor não deve transparecer nenhuma impressão autoritária sobre o interlocutor. Quando o locutor considerar necessário entrar em assunto que seja da alçada do interlocutor, deve pedir permissão, sem invadir o território alheio.

2. Ofereça alternativas! Use a deferência! Neste caso, o locutor permite que o interlocutor tome suas próprias decisões sobre as possíveis interpretações da mensagem. Dessa forma, o locutor não parecerá impositivo, pois permitirá que o interlocutor tenha liberdade de ação. $\mathrm{O}$ emprego de eufemismos tem o objetivo de dar ao interlocutor a opção de não entender e, sendo assim, optar por outra interpretação da mensagem.

3. Seja amigável! Empregue a camaradagem! O interlocutor deve sentir-se bem por meio de um comportamento amistoso. Esta máxima busca dar ao interlocutor certa comodidade na interação ou, também, pode ter por objetivo deixá-lo à vontade durante a interação, por meio da aproximação.

A primeira máxima - Não imponha! - aplica-se, especialmente, nas situações formais, nas quais há uma evidente diferença social ou falta de intimidade entre os interlocutores. Em geral, pedimos autorização para fazer ou dizer algo que não seja de nossa alçada. São formas linguísticas que criam uma sensação de distanciamento entre os interlocutores.

A segunda - Ofereça alternativas! - aplica-se, principalmente, quando há equilíbrio social entre os interlocutores e não há familiaridade ou confiança. 
Oferecer alternativas equivale a apresentar as coisas de maneira que a recusa da própria opinião ou oferta não seja sentida como polêmica. Dessa forma, permite-se que o interlocutor tome suas próprias decisões, por isso deixam-se abertas várias opções. O eufemismo permite, por um lado, que o interlocutor tenha toda a liberdade para tomar uma decisão e, por outro, evita que o locutor se abstenha de impor sua autoridade, evitando o risco de ofender o interlocutor.

A terceira - Seja amistoso! - aplica-se às situações em que a relação entre os interactantes seja próxima. Tal máxima produz uma sensação de igualdade, fazendo que o interlocutor sinta-se bem. Justifica-se, por esta máxima, o emprego de formas de tratamento que conduzem a uma sensação de igualdade e confiança.

Segundo Escandell Vidal (1996, p. 136), cortesia pode entender-se por um conjunto de normas sociais, estabelecidas pela sociedade, e que regulam o comportamento adequado de seus membros, proibindo algumas formas de conduta e favorecendo outras. $\mathrm{O}$ que se ajusta às normas poder ser considerado cortês; o que não se ajusta, descortês. Para a autora, um dos aspectos que mais reflete a interrelação entre cortesia e formas linguísticas são as formas de tratamento ou dêiticos sociais. Por isso é necessário ajustar as formas de tratamento às normas sociais, ao contexto situacional e aos interesses dos interactantes.

Assim, o efeito cortês ou descortês dependerá da existência de uma norma cultural específica, relativa à forma ou ao conteúdo do enunciado e, também, ao grau de ajuste do enunciado à referida norma. Para chegar à conclusão se um ato de fala é cortês ou descortês, é necessário considerar os conhecimentos de natureza cultural.

Lindley Cintra considera como "formas de cortesia", somente, aquelas que estão revestidas de formalidade. Cremos, no entanto, que não é, propriamente, a formalidade ou a forma em si a que está revestida de aspecto cortês ou descortês. Entendemos que não se pode dizer que esta ou aquela forma estão marcadas pela cortesia, pois é a situação de uso que assinalará que tal forma de tratamento será cortês ou descortês. Nas escolas dos grandes centros urbanos do Brasil, o emprego do tratamento formal a senhora pode gerar duplo sentido. Se o aluno assim o faz, corre o risco de dar a entender que considera a professora velha, pois esta pode replicar: "Está me chamando de velha? Trate-me por você". Dessa forma, o tratamento a senhora que, há alguns anos, seria cortês, hoje, pode ser descortês.

Kerbrat-Orecchioni (2006, p. 101) enfatiza que a finalidade da cortesia é reduzir ao máximo o possível antagonismo entre os interactantes e desarticular, pelo menos em parte, os possíveis conflitos que ameaçam surgir, em qualquer momento, durante o desenvolvimento da interação. Briz Gómez (2004, p. 67) ressalta que a cortesia verbal é uma estratégia dentro das atividades de imagem do locutor e do interlocutor e que está regulada em cada cultura e grupo social por certas convenções, a partir das quais um comportamento linguístico pode ser avaliado como cortês ou descortês. Segundo o autor, tal avaliação dependerá da situação na qual está inserida a interação, já que o que é considerado como cortês ou descortês não pode ser interpretado a partir do ato de fala isolado.

Blas Arroyo (1994), ao comentar as formas de tratamento no espanhol ibérico, afirma que o grande mérito do modelo de Lakoff está no fato de mostrar que não só o pronome de tratamento formal faz parte do modelo de cortesia, mas também o pronome informal.

En la obra de Lakoff, la cortesía no se aborda únicamente como una muestra de reverencia o respeto por parte del hablante, sino como un fenómeno pragmático que preside aquellas estrategias lingüísticas destinadas a reducir la tensión que todo intercambio interactivo comporta. $\mathrm{Y}$ en este sentido, aun reconociendo sus diferentes significaciones psicosociales, ambos pronombres están vinculados a la manifestación de un mismo objetivo conversacional (BLAS-ARROYO, 1994, p. 14).

Também, segundo Blas Arroyo (1994), outro mérito do trabalho de Lakoff é permitir explicar as diferenças nos graus de aplicação das máximas entre as distintas comunidades, grupos sociais e, também, considerar um único falante. Dessa forma, pode-se explicar a maior frequência do tratamento informal entre os jovens e as classes médias e altas, em contraste com os usos mais conservadores e tradicionais entre as faixas etárias mais elevadas e entre as classes menos favorecidas.

\section{Análise do corpus}

Como corpus deste trabalho, escolhemos três obras de teatro do final do século XX. Duas foram escritas pelo dramaturgo brasileiro Nelson Rodrigues e a outra por Mauro Rasi. Cremos que tais obras retratam os costumes brasileiros do fim do século XX e, dessa forma, será possível fazer paralelos com o espanhol, ao compararmos resultados com trabalhos similares para o espanhol ibérico, especialmente o de Pedroviejo Esteruelas (2004).

Dados obtidos de Silva (2002) mostram que, no Brasil, assim como ocorreu na Espanha, há uma tendência à informalidade no que diz respeito aos tratamentos entre filhos e país. A situação brasileira, no entanto, não está, ainda, tão definida como a espanhola, já que é a geração mais jovem e feminina a que tende mais ao uso 
do tratamento informal. Os exemplos retirados da peça "Anti-Nelson Rodrigues" comprovam essa constatação. A personagem Oswaldinho usa o tratamento formal $o$ senhor/ a senhora para se dirigir aos seus pais, enquanto a personagem Joice usa o informal você. Ressalte-se que os dois têm entre 25 e 28 anos de idade.

Exemplo (1):

Oswaldinho: A senhora me chamou de ladrão.

Tereza: Ouve sua mãe. É o seguinte: às vezes, as palavras falam demais. Dizem mais do que eu queria dizer. Mas agora eu estou dando. Juro por tudo. Juro por minha mãe, pela alma de minha mãe. Pode levar, Oswaldinho.

Oswaldinho: Mamãe, você

Tereza: (Interrompendo impulsivamente) Ainda bem que você me chama de você. Meu filho, quantas vezes lhe disse para não me chamar de senhora?

(“Anti-Nelson Rodrigues”, p. 476)

A mãe de Oswaldinho insiste para que o filho a trate de você, ainda que ele hesite em fazê-lo. Em outros momentos, vê-se que Oswaldinho somente empregará a variante você, de forma consciente, pois, espontaneamente, usará a forma a senhora. Outras vezes, haverá alternância entre as duas formas. Ressalte-se que a mãe insiste que o filho a trate de você para mascarar a idade própria de uma mãe de um jovem de 28 anos. Este jogo de afastamento-aproximação entre os interactantes será, desde uma perspectiva pragmassocial, quase igual em espanhol, porém, mudando os pronomes ou, quando possível, suprimindo-os. Assim, na fala de Oswaldinho "A senhora me chamou de ladrão", as possibilidades seriam "Ø Me dijo ladrón/ Usted me dijo ladrón". Na segunda das falas do jovem, a forma em espanhol é muito semelhante, a saber: "Tú, mamá /Mamá, tu". Tampouco haverá problemas na fala da mãe que, em espanhol, pode ser traduzida assim: "Mi hijo ¿cuántas veces te dije que no me trataras de usted?

No próximo exemplo, há um diálogo mais ríspido entre Joice e seu pai, no qual ocorre um ato falho da filha, pois ela emprega a forma o senhor e, imediatamente, a substitui pela forma você.

\section{Exemplo (2):}

Joice: Papai, você me conhece? Tem certeza que me conhece? Olha para mim, papai. Não vira o rosto. Olha. Salim: (Olhando-a, finalmente) Estou olhando.

Joice: Você acredita ou não acredita em mim? (Salim está fazendo, automaticamente, o sinal da cruz) $\mathbf{O}$ senhor acha. Chamei você de senhor. Você acha que o dinheiro vai me corromper?

(“Anti-Nelson Rodrigues”, p. 495)
Como se pode observar, a filha corrige seu ato falho e volta à forma de tratamento informal, reforçando tal mudança pelo emprego do pronome você duas vezes: "Chamei você de senhor. Você acha..."

A indicação de proximidade entre os participantes no enunciado "Papai, você me conhece?" em espanhol seria marcada pelo uso da segunda pessoa do singular $(t u)$, porém, como dito anteriormente, omitindo o pronome, dado que, nesta língua, predominam os enunciados com sujeito nulo, deixando a referência dêitica por conta da terminação verbal: "Papá, ¿ Ø me conoces?" Todavia, existe em espanhol a alternativa de explicitar o sujeito como marca lingüística, com a finalidade de provocar estratégias de compreensão específicas (CORREA, 2010, p. 33), que, neste contexto, nada mais é do que enfatizar a acusação: “Papá ¿tú me conoces?”. Desta forma, a relação entre os enunciados em português e espanhol, se empregados os pronomes pessoais, são pragmaticamente dissímiles. O mesmo acontece em: "Você acredita ou não acredita em mim?", cuja tradução mais próxima omitiria o pronome $t u$ : “¿Ø Me crees o no me crees?” Se optarmos pela explicitação do pronome (" $¿$ Tú me crees o no me crees?"), repetir-se-á o efeito pragmático visto no enunciado anterior.

Quanto à última das falas da Joice ("O senhor acha. Chamei você de senhor. Você acha que o dinheiro vai me corromper?"), encontramos maiores nuances na tradução: "Usted cree. Te he tratado de usted. ¿ Ø Crees que el dinero va a corromperme?" Na primeira parte do enunciado, a forma usted embora não obrigatória, se faz necessária. Agora em "Chamei você de senhor", o pronome tú é agramatical, somente sendo possível a forma tônica a ti: "\# He tratado tú de usted" / "Te he tratado a ti de usted" ou "A ti te he tratado de usted". Com o emprego da forma tônica, também se produz uma marcação do foco enunciativo com a finalidade pragmática já vista. $\mathrm{O}$ mesmo fenômeno acontece se explicitarmos o pronome tú em "¿Tú crees que el dinero va a corromperme?"

Também, é possível encontrar interações marcadas pela relação de poder, nas quais o interactante, situado em posição hierarquicamente superior, recebe o tratamento formal, mas devolve um tratamento igualmente formal, respeitando a Máxima 1 de Lakoff ("Não imponha! Mantenha a distância!), como se observa no início do exemplo a seguir.

Exemplo (3):

Oswaldinho: Entramos nesta casa quase ao mesmo tempo? Se não me engano, a senhora começou na véspera?

Joice: Sim, um dia antes.

Oswaldinho: Aliás, preciso explicar. Não estranhe a mudança de tratamento. Pretendo chamá-la de dona e 
senhora na presença dos outros. E de você e de Joice, quando estivermos sozinhos, como agora.

Joice: $\mathbf{O}$ senhor é quem sabe.

(Anti-Nelson Rodrigues, p. 488)

Como se trata do primeiro encontro entre patrão (Oswaldinho) e a empregada (Joice), há, inicialmente, uma intenção de respeitar a Máxima 1. O patrão, contudo, como deseja ser amigável e colocar sua empregada à vontade, deixa de lado o tratamento formal e usa o tratamento informal. É necessário enfatizar que Oswaldinho tinha intenção de seduzir sua empregada, por isso pede que ela, também, use o tratamento informal você, no entanto ela recusa usar essa forma.

Estas estratégias comunicacionais em espanhol também são plausíveis de serem realizadas, mediante as formas de tratamento com as restrições vistas anteriormente. Assim em: "Se não me engano, a senhora começou na véspera?" pode ser traduzida quase que literalmente assim: "Si no me engaño, ¿usted comenzó en la víspera?". Gramaticalmente, poderia suprimir-se o pronome usted mas, como em português, a intenção comunicativa, neste contexto, é marcar a formalidade no trato, a melhor alternativa é deixá-lo explícito também em espanhol. O mesmo acontece com a resposta da Joice que mantém a formalidade: "Usted sabe".

Exemplo (4):

Oswaldinho: Agora, que estamos sozinhos, quero que você me chame de você.

Joice: Importa muito que eu chame o senhor de você? Oswaldinho: Se importa, ou não importa, é comigo. Quero assim.

Joice: Dr. Oswaldo, prefiro chamá-lo de senhor.

(Anti-Nelson Rodrigues, p. 488)

O uso da forma você também pode ser uma manifestação de cortesia, quando o locutor, seguindo a Máxima 3 (Seja amigável! Empregue a camaradagem!), deseja estreitar os vínculos de solidariedade, amizade ou confiança com seu interlocutor. Como a empregada não percebeu as intenções do patrão, recusa o tratamento informal e insiste no tratamento formal: doutor e senhor. Se pensarmos em espanhol, a primeira fala do Oswaldinho e a ultima da Joice exigiriam somente a troca dos pronomes você por tú e o senhor por usted. Entretanto, o mesmo não é possível em: "Importa muito que eu chame o senhor de você?". Neste caso, o pronome de tratamento o senhor tem que ser traduzido pelo pronome de objeto direto lo: “¿Es importante que lo trate de tú?" Neste caso, também, se quisermos manter o pronome usted, com a consequente variação pragmática, ele assumirá a forma tônica mantendo-se o pronome $l o$ necessariamente: “¿Es importante que lo trate de tú a usted?"

Exemplo (5):

Humberto: Viu? Não adianto. Fique onde está, quietinha!

Lídia: Deixa eu passar! Indigno!

Umberto: Diz isso e quando acaba_ gosta de mim!

Lídia: Eu?

Umberto: As mulheres são engraçadíssimas!

Lídia: Está doido!

Umberto: Doido coisa nenhuma... Você...

Lídia: Não me chame de você!

Umberto: Chamo, sim. Você, ouviu? Você... Você gosta de mim e sabe disso.

(“A mulher sem pecado", p. 332)

O fragmento retrata uma cena em que Umberto, motorista da família, aproveita a distração da patroa e a beija. Lídia esquiva-se, tentando sair da sala, mas Umberto não permite e afirma que a patroa está apaixonada por ele. Ela, indignada, afirma que ele está louco e, nesse momento, ele vai dizer algo, mas suspende a voz e trata a patroa por meio do pronome você. Como há uma relação de poder entre eles, Lídia o repreende por haver sido tratada pelo informal você, inadequado para a relação entre patroa e empregado. Ao usar a forma você, Umberto foi descortês e inadequado, violando a Máxima 1, invadindo o território pessoal da patroa. Depois da repreensão, o motorista insiste na forma você, repetindo-a, mostrando-se, ainda mais, desrespeitoso. No entanto, se considerarmos que Umberto quer enfatizar a relação íntima e amorosa entre ele e a patroa, ao usar o você, respeitará a Máxima 3, rompendo, dessa forma, a distância que há entre eles, provocada pela relação profissional. Umberto deseja marcar a aproximação com Lídia, por isso a forma você selaria a nova situação. Ressalte-se que a reprimenda de Lídia se deve a visões diferentes: enquanto ela, naquele momento em que está aborrecida, considera Umberto, apenas, como seu empregado, ele, ao contrário, deseja salientar que, naquele momento, representa o papel de amante e não de empregado. Com este exemplo, é possível concluir que o emprego do tratamento formal ou informal dependerá do papel social representado pelos interactantes da conversação e pela contexto específico.

Novamente encontramo-nos com casos em que uma simples substituição de pronomes daria conta de uma tradução que manteria equivalências tanto nos aspectos sociopragmáticos como pragmalinguísticos. Contudo, há uma ressalva a se fazer em "Você gosta de mim e sabe disso", uma vez que as construções sintáticas com o verbo gostar são diferentes no espanhol usual "'(Yo) Te gusto y lo sabes". Por esse motivo, em espanhol, a marca de 
informalidade no tratamento é dada pelo pronome te - do verbo gostar -, reservando a forma le para a formalidade "(Yo) Le gusto y lo sabe". A tradução literal "Tú gustas de mí y lo sabes" pressupõe a opção por uma linguagem artificial, com as consequentes implicações pragmáticas (efeito humorístico, etc.).

Após analisar as estratégias pragmáticas de aproximação e distanciamento social que as formas de tratamento permitem, apontaremos alguns aspectos da ocorrência de tais formas no português do Brasil e no espanhol.

Alba de Diego y Sánchez Lobato (1980) realizaram um estudo sobre as formas de tratamento no espanhol peninsular. Segundo os autores, $100 \%$ dos informantes declararam usar o pronome solidário e informal na relação com os pais, independente de qualquer variável. No Brasil, depois do período de democratização e de expansão da televisão como meio de comunicação de massa, o tratamento de filhos em relação aos pais, está mudando significativamente, de forma especial nos grandes centros urbanos. Estudos realizados por Silva (2002) mostram que, na região metropolitana de São Paulo, há uma grande tendência para o tratamento informal dos filhos em relação aos pais, pois, entre as faixas mais jovens, cerca de $70 \%$ dos informantes admitiram o tratamento informal - você - na relação com os pais.

É evidente que, nas comunidades mais distantes dos grandes centros urbanos, há uma maior resistência ao tratamento solidário em relação aos pais, já que pode representar, dependendo dos costumes, falta de respeito. Mesmo nesses centros mais distantes, já se notam sinais claros de mudança em relação ao uso da forma você.

Nas peças de teatro analisadas, obtivemos os seguintes resultados:

Quadro 1. Formas de tratamento usadas na relação entre pais e filhos, "Anti-Nelson Rodrigues"

\begin{tabular}{|l|c|c|}
\hline & Tu & O Senhor / A Senhora \\
\hline De pais a filhos & 100 & 0 \\
\hline De filhos a pais & 64 & 36 \\
\hline
\end{tabular}

Quadro 2. Formas de tratamento usadas na relacão entre pais e filhos, "Pérola"

\begin{tabular}{|l|c|c|}
\hline & Tu & O Senhor / A Senhora \\
\hline De pais a filhos & 100 & 0 \\
\hline De filhos a pais & 100 & 0 \\
\hline
\end{tabular}

A partir dos quadros, é possível perceber que, entre a peça "Anti-Nelson Rodrigues", de 1973, e a peça "Pérola", de 1995, há, como já constataram Alba de Diego e Sánchez Lobato para o espanhol peninsular, uma rápida evolução em direção ao uso do tratamento informal entre filhos e pais. Comparando com os dados obtidos em Pedroviejo Esteruelas (2004), percebe-se que os resultados são muito próximos.

Com tais considerações, constatamos que a evolução das formas de tratamento no Brasil, no final do século XX, é semelhante ao que já ocorreu no espanhol peninsular em meados do século passado.

\section{Consideracões finais}

Do estudo apresentado, notamos que, estruturamente, os aspectos da cortesia em espanhol e português são muito parecidos quanto às formas de tratamento, porém há de se ressaltar que a grande dificuldade está na estrutura morfossintática com a qual se constroem os enunciados e também com a não equivalência semântica entre os pronomes de tratamento você -usted, observadas nos exemplos já comentados. Há, também, uma distorção no uso dos elementos corteses por parte dos falantes do português do Brasil ao empregarem tais formas, como foi demonstrado nos exemplos acima.

Assim, podemos considerar que a aquisição/aprendizagem não passa somente pelo ato de aprender a estrutura, há que superar a interferência da interlíngua, há de observar os mecanismos de uso pragmático desses recursos e, principalmente, é preciso saber interagir de forma adequada à situação. Todos esses fatores unidos demonstram a complexidade de uso de L2 e a necessidade de práticas interacionais sobre os diversos temas da linguagem.

Como visto, os aspectos da cortesia em espanhol e português são muito parecidos quanto às estratégias sociopragmáticas para marcar distanciamento ou proximidade, mediante e emprego das formas de tratamento. Contudo, esses dêiticos sociais têm "assimetrias" no que se refere às escolhas pragma-linguísticas para sua construção. De fato, como visto, além da não equivalência semântica dos pronomes você-usted, a grande dificuldade está nas estruturas morfossintáticas que o aprendente brasileiro traz internalizadas da sua língua materna, as quais não se correspondem com as formas do espanhol. Por outro lado, as formas que se correspondem exigem, como apontamos, uma forte especulação reflexiva, uma vez que, pelo fato de não serem "naturais" (por vezes "artificiais") no português do Brasil, não garantem seu sucesso por serem de difícil construção na L2. Assim, por exemplo, um corriqueiro Estoy esperándolo/Lo estoy esperando, possibilidades quase únicas em espanhol, soam muito artificiais se calcadas no português do Brasil: Estou esperando-o / O estou esperando, língua na qual se prefere o emprego do sujeito pronominal, Estou esperando o senhor. 


\section{Referências}

DIEGO, Vidal Alba de; LOBATO, Jesús Sánchez. Tratamiento y juventud en la lengua hablada: aspectos sociolingüísticos. Boletín de la Real Academia Española, v. 60, p. 95-129, 1980.

ALMEIDA FILHO, José Carlos Paes. Uma metodologia específica para o ensino de línguas próximas? In: Português para Estrangeiros: Interface com o Espanhol. Campinas: Pontes, 1995.

BLAS ARROYO, José Luis. Los pronombres de tratamiento y la cortesía. Revista de Filología, v. 13, p. 7-35, 1994.

BRIZ GÓMEZ, Antonio. Cortesía verbal codificada y cortesía verbal interpretada en la conversación. In: BRAVO, Diana; BRIZ GÓMEZ, Antonio (Org.). Pragmática sociocultural: estudios sobre el discurso de cortesía en español. Barcelona: Ariel Lingüística, 2004. p. 67-93.

BROWN, Roger; GILMAN, Albert. The pronouns of power and solidarity. In: Style in language. Cambridge: MIT Press, 1960. p. 253-276.

CORREA, Paulo Antonio Pinheiro. Dimensiones sintácticas de español: su interacción con el discurso y el aprendizaje por hablantes de portugués. Maringá: Eduem, 2010.

CUNHA, Celso Ferreira da. Gramática da língua portuguesa. 2. ed. Rio de Janeiro: FENAME, 1975.

TULLIO, Angela Di. Manual de gramática del español. 2. ed. Buenos Aires: La Isla de la Luna, 2007.

VIDAL, María Victoria Escandell. Introducción a la pragmática. Barcelona: Ariel, 1996.

FANJUL, Adrián Pablo. Conhecendo assimetrias:a ocorrência de pronomes pessoais. In: FANJUL, Adrián Pablo; GONZÁLEZ, Neide Maia (Org.). Espanhol e português brasileiro: estudos comparados. São Paulo: Parábola, 2014. p. 29-51.

ANDRADE NETA, Nair Floresta. Aprender español es fácil porque hablo portugués: Ventajas y desventajas de los brasileños para aprender español. 2012. Disponível em: $<$ http:// www.cuadernoscervantes.com/lc portugues.html>. Acesso em: 06 abr. 2017.

FRASER, Bruce. Pragmatic competence: the case of hedging. In: KALTENBOCK, Gunther; MIHATSCH, Wiltrud Mihatsch; SCHNEIDER, Stefan (Ed.). New Approaches to Hedging. Emerald Group Publishing Limited, 2010. Disponível em: $<$ http://
www.bu.edu/sed/files/2010/10/2010-Pragmatic-CompetenceThe-Case-of-Hedging.pdf> . Acesso em: 06 abr. 2017.

GONZÁLEZ, Neide Maia. Pero ¿qué gramática es ésta? Los sujetos pronominales y los clíticos en la interlengua de brasileños adultos aprendices de español/LE. Rilce. Revista de Filología Hispánica. Español como lengua extranjera: investigación y docencia, v. 14, n. 2, p. 243-263, 1998.

KERBRAT-ORECCHIONI, Catherine. Análise da Conversação: princípios e métodos. São Paulo: Parábola, 2006 [1986] v. 16.

KRASHEN, Stephen. Principles and Practice in Second Language Acquisition. Oxford, Pergamon, 1982.

LAKOFF, Robin. The logic of politeness: or minding your p's and q's. Papers from the Ninth Regional Meeting, Chicago Linguistic Society, v. 9, p. 292-305, 1973.

CINTRA, Luís Filipe Lindley. Sobre "formas de tratamento" na língua portuguesa. Lisboa: Livros Horizonte, 1972.

MAGALDI, Sábato. Teatro completo de Nelson Rodrigues. Rio de Janeiro: Nova Aguilar, 1994.

ESTERUELAS, Juan Manuel Pedroviejo. Formas de tratamiento em dos obras de teatro Del siglo XX: Historia de uma escalera y Bajarse al moro. In: BRAVO, Diana; GÓMEZ, Antonio Briz (Ed.). Pragmática sociocultural: estúdios sobre El discurso de cortesia em español Barcelona: Ariel Lingüística, 2004. p. 245-262.

RASI, Mauro. Pérola. Rio de Janeiro: Record, 1995.

ROBINSON, W. P. Linguagem e comportamento social. São Paulo: Cultrix, 1977.

SILVA, Luiz Antônio da. Formas de tratamento familiar no português brasileiro. 2002.

SCHÜTZ, Ricardo. Assimilação natural x ensino formal. English Made in Brasil, 2006. Disponível em: <http://www. sk.com.br/sk-laxll.html>. Acesso em: 06 abr. 2017.

PATTEN, Bill Van; BENATI, Alessandro G. Key Terms in Second Language Acquisition. London: Continuum, 2010.

Recebido: 03 de março de 2017

Aprovado: 24 de abril de 2017

Contato:

Luiz Antônio da Silva <luizs@usp.br>

Ramiro Carlos Humberto Caggiano Blanco <ramirocagginob@gmail.com> Yedda Alves de Oliveira Caggiano Blanco <yeddablanco@hotmail.com> 